2014-06

\title{
Cultural responses to pain in UK children of primary school age: A mixed-methods study
}

\section{Azize, PM}

http://hdl.handle.net/10026.1/12841

10.1111/nhs. 12084

Nursing \&amp; Health Sciences

Wiley

All content in PEARL is protected by copyright law. Author manuscripts are made available in accordance with publisher policies. Please cite only the published version using the details provided on the item record or document. In the absence of an open licence (e.g. Creative Commons), permissions for further reuse of content should be sought from the publisher or author. 


\title{
Research Article
}

\section{Cultural responses to pain in UK children of primary school age: A mixed-methods study}

\author{
Pary M. Azize, RN, BSc, MSc, PhD, ${ }^{1,2}$ Ruth Endacott, RN, DipN(Lond), MA, PhD, ${ }^{2,3}$ Allegra Cattani, BSc, MSc, PhD $^{2}$ \\ and Ann Humphreys, RN, MA, $\mathrm{PhD}^{2}$ \\ ${ }^{1}$ Sulaimanea Polytechnic University, Sulaimenea, Iraq, ${ }^{2}$ Faculty of Health, Education \& Society, Plymouth University, \\ Plymouth, UK and ${ }^{3}$ School of Nursing \& Midwifery, Monash University, Melbourne, Victoria, Australia
}

\begin{abstract}
Pain-measurement tools are often criticized for not addressing the influence of culture and ethnicity on pain. This study examined how children who speak English as a primary or additional language discuss pain. Two methods were used in six focus group interviews with 34 children aged 4-7 years: (i) use of drawings from the Pediatric Pain Inventory to capture the language used by children to describe pain; and (ii) observation of the children's placing of pain drawings on red/amber/green paper to denote perceived severity of pain. The findings demonstrated that children with English as an additional language used less elaborate language when talking about pain, but tended to talk about the pictures prior to deciding where they should be placed. For these children, there was a positive significant relationship between language, age, and length of stay in the UK. The children's placement of pain drawings varied according to language background, sex, and age. The findings emphasize the need for sufficient time to assess pain adequately in children who do not speak English as a first language.
\end{abstract}

Key words children, language, narrative analysis, pain measurement, pain, Pediatric Pain Inventory, English as an additional language.

\section{INTRODUCTION}

The assessment of pain in children has been an enduring theme in the research literature over many decades, with particular focus on how pain can be adequately measured and the extent of undermeasurement of pain (McCaffery \& Beebe, 1989; American Academy of Pediatrics: American Pain Society, 2001; Coyne, 2006; Subhashini et al., 2009). Children's pain is often undertreated (Stalnikowicz et al., 2005; Drendel et al., 2006; Taylor et al., 2008), which might cause anxiety and distress for the caregiver (Subhashini et al., 2009). Arguably, depending on cultural background, not all children might experience the same level of pain (Bates et al., 1993; Zinke, 2007); the impact of family and cultural beliefs on how children learn to react to pain has been debated (Edwards et al., 2001; Fortier et al., 2009). However, race and ethnicity have been identified as risk factors for the underuse of analgesia (Bonham, 2001); for example, in one study, Hispanic children tended to be undertreated for pain when compared with their nonHispanic peers (Green et al., 2003).

Correspondence address: Ruth Endacott, School of Nursing \& Midwifery, Plymouth University, Rolle Building, Level 4, Drake Circus, Plymouth PL4 8AA, UK. Email: ruth.endacott@plymouth.ac.uk

Received 9 March 2013; revision received 5 June 2013; accepted 14 June 2013.

\section{Study aims and research questions}

This study aimed to examine how primary school-age children who speak English as a primary or additional language perceive, express, and explain pain. The study aim was addressed through the following research questions: (i) How do primary school-age children talk about pain?; (ii) What are the similarities and differences in the language used to talk about pain by children with English as a primary and additional language?; and (iii) Are there differences in the perceptions of pain by children of different age, sex, language background, and country of birth?

\section{Study design and methods}

The study objectives were addressed using a mixed-methods design. Two methods were used in focus group interviews with groups of primary school children: (i) use of drawings from the Pediatric Pain Inventory to measure children's rating of situations that are likely to cause pain (pictureplacement activity; PPA); and (ii) use of a small sample of drawings from the PPA to trigger discussion and capture the language used by children to talk about pain.

The mixed-methods design chosen is dependent on decisions made in four dimensions: theorizing, relative weight of data sources, timing of data collection and integration of data (Creswell \& Plano Clark, 2007). The theory underpinning this study was the sociocommunication model of pain 
(Hadjistavropoulos \& Craig, 2002), explored in greater detail in Azize et al.'s (2011) study. In order to identify which pictures would trigger most discussion, the PPA was conducted first; field notes were collected by an observer during this activity. In light of these decisions, a sequential explanatory mixed-methods design was used. Data were collected using focus group interviews, as this was likely to generate more narrative than individual interviews; this approach has been previously used to discuss sensitive topics with children (Hoppe et al., 1995).

\section{METHODS}

\section{PPA}

The Pediatric Pain Inventory (Lollar et al., 1982) comprises a series of hand-drawn pictures, originally developed to measure perceptions of pain in hospitalized children, and validated for this age group. The full inventory consists of 24 line drawings in four settings (medical, recreational, activities of daily living, and psychosocial), each depicting a potentially-painful event. The medical drawings were omitted for this study, as the purpose was to examine the language that children use to describe pain, rather than evoke memories of their own painful medical experiences. The drawings depict situations that might result in pain; for example, a child falling from a bicycle, rather than focusing on facial expressions. The drawings show blank faces to avoid emotional cues, and are non-specific with respect to sex. Validity and reliability for the inventory were established by the original authors. Internal consistency was computed for intensity and duration with all four types of settings (medical, recreational, activities of daily living, and psychosocial), with alpha coefficients ranging from 0.41 to 0.76 for intensity, and 0.49 to 0.70 for duration of pain. The lowest alpha coefficients in each case were for the drawings depicting medical pain (0.41 and 0.49 ), the drawings that were omitted for this study. ANOVA was used to assess differences between the levels of pain for the four settings. The means were significantly different, both for intensity $(F[3,1499]=114.4, P<0.001)$ and for duration $(F[3,1447]=148.9, P<0.001)$. In particular, psychosocial pain was perceived as significantly less intense than other types of pain, and medical pain was perceived to last longer (Lollar et al., 1982).

Groups of children were encouraged to look at each picture and decide whether it should be placed on a red, yellow, or green paper, depending on the perceived level of pain intensity. The colored papers were explained as representing different levels of pain. The observer recorded field notes during this activity.

\section{Group discussions}

The group discussions allowed the researchers to explore and compare how different groups describe and discuss pain, and to assess whether children with English as an additional language (EAL) use different linguistic expressions to describe pain. The group discussions used three-to-four pictures from the PPA to generate further discussion about pain, using the following questions: (i) What would the child in the picture say?; (ii) What would the child in the picture tell Mommy or Daddy?; (iii) What would Mommy or Daddy do?; and (iv) What would happen then?

\section{Sample}

The research questions were addressed through data collection with primary school-aged children (4-7 years) with English as a primary/sole language (monolingual) and speaking EAL. Data collection took place in a primary school that included different nationalities. Data collection took place in one monolingual and one EAL group for each of three year groups (foundation year, Year 1, and Year 2), a total of six groups. Children were sampled according to school year (foundation year $=4-5$ years, Year $1=5-6$ years, and year $2=6-7$ years), rather than age, thus data are presented using this nomenclature throughout this study. The separation of language and age groups was a deliberate attempt to reduce any dominance of English over EAL speakers (or vice versa) to ensure the voices of all child participants were heard. Both methods of data collection were piloted with a sample similar to the study participants; no changes were made to the methods as a result of the pilot.

\section{Demographic data}

In order to interpret the study findings, a number of demographic details were collected using a brief questionnaire completed by parents at the time of consent. These items were chronological age, length of time at the school, length of residence in the UK and language spoken at home by both parents. Following the PPA and group discussions, the vocabulary of each individual child was assessed using a standardized lexical test (British Picture Vocabulary Score version II; BPVS II) (Dunn et al., 1997). These data were collected solely for the purpose of the study and were not included in the child's portfolio at the school.

Assessing language comprehension needs to be specialized for EAL children; there is very little research on assessing second-language acquisition, especially in terms of culturallyappropriate assessment instruments (Espinosa, 2005; Chan \& Sylva, 2006). The BPVS II is considered to be an appropriate valid and comparable instrument to assess receptive language among this population. The test uses multiple-choice responses to standardize the assessment of encoding and decoding vocabulary, and can be used with children aged 3-8 years. The test consists of a total of 168 stimulus words that are arranged in 14 sets of 12 items. The children are asked to point to the picture that they think best represents the word spoken by the tester. A median split-half reliability of 0.86 was reported for the 2571 pupils in the standardization sample for the original test (Dunn et al., 1997).

Data collection was timed to fit in with the usual school timetable, thus took place over a total of eight days. To familiarize themselves with the school environment and prepare the children for the researchers' presence, the researcher and observer spent some time in the classrooms in the two weeks preceding data collection. Each focus group interview took 
between 30 and $50 \mathrm{~min}$, and the individual BPVS II test with each child took 15-20 min.

\section{Data analysis}

\section{PPA data}

Simple tabulation was used to summarize the PPA data. In keeping with Lollar's original method (Lollar et al., 1982), the children were not encouraged to use numerical values when placing the drawings, thus the data were treated as categorical for analysis purposes.

\section{Narrative data}

Primary schools in England use narration to assess the linguistic abilities of monolingual and EAL children (Perez \& Tager-Flusberg, 1998), and the children used stories throughout the focus group interviews. Thus, narrative analysis was used to examine the focus group data and field notes taken by the observer during the PPA. Narrative analysis is credited with telling a story in a far more detailed and realistic way than can be captured by the isolation of themes and the use of content analysis (Bochner, 1997). Narratives have a way of speaking for themselves, as they are rooted in culture and nuances of the individual (Van Maanen, 1988). For the purpose of this study, principles of narrative analysis underpinned identification of key words used by monolingual children and children with EAL, thus qualitative data are presented according to the type of narrative, rather than by theme. The analysis steps were as follows: (i) transcribe the focus group interviews; (ii) analyze the content of the discussion for a variety of themes using a coding scheme; (iii) identify consistencies and inconsistencies within the overall narrative; (iv) combine the interview transcripts and observer notes to identify the emphasis or intensity of the participants' comments and to differentiate between individual opinions and group agreement; (v) relisten to the audio files to ensure that the form (manner in which the story is told) is adequately captured; and (vi) Reread the narratives to identify the language that the children employed to talk about pain.

\section{Ethical considerations}

The principles outlined by Doyle (2000) for conducting research with children were used as a guide for ensuring ethical integrity. Data collection was undertaken by a member of the team with an understanding of the cognitive development and emotional and social needs of children (PA, a children's nurse). Consent was obtained from parents for their child's involvement in the study, and verbal agreement was given by the children. The research team also provided information sessions for parents and teachers to explain the study. Confidentiality was discussed with the children at the beginning of each focus group, and all data excerpts were anonymized. The pictures and interview questions were discussed with the teachers to highlight any potential for psychological harm; medical pictures were removed, because these did not meet the aims of the study, and a further picture depicting a child touching an electrical socket was removed upon advice of the teachers. Using the usual school setting for data collection and allowing the children to stay in groups was also felt to optimize the child's comfort during data collection. The study was approved by the university Faculty of Health human research ethics committee.

\section{RESULTS}

\section{Demographic data}

Across the whole sample $(n=34), 59 \%$ of children were monolingual (English), and approximately half of each language group was female (50\% of monolingual children and $47 \%$ of EAL children). For the EAL children $(n=15)$, the language spoken to the child at home was predominantly Arabic or Kurdish ( $n=8$ mothers and $n=9$ fathers).

\section{BPVS II data}

The mean BPVS II scores for all participants according to sample group are summarized in Table 1 . The language age was lower for EAL children across year groups, with the largest difference between monolingual and EAL study participants in the formulation year and Year 2 children. Following conventions for BPVS II data, raw scores were converted into language age. Using the norms for BPVS II provided by Dunn et al. (1997), 67.64\% of the language ages for the study participants were in the normal range (85-119).

\section{Relationships between BPVS II scores and demographic data}

The calculated language age of English lexical comprehension (BPVS II score) of monolingual children ( mean $=69.85$, standard deviation $=19.27$ ) was significantly higher than EAL children $($ mean $=47.93$, standard deviation $=14.32$;

Table 1. Mean British Picture Vocabulary Score version II language age in months by school year and language background

\begin{tabular}{lccccccccc}
\hline & \multicolumn{3}{c}{ Foundation year } & \multicolumn{2}{c}{ Year 1 } & \multicolumn{2}{c}{ Year 2 } & \multirow{2}{*}{ Total } \\
& M & EAL & M & EAL & M & EAL & M & EAL \\
\hline Participants $(n=37)$ & 5 & 4 & 8 & 3 & 7 & 7 & 20 & 14 \\
Mean language age in months (SD) & 55 & 39 & 68 & 63 & 83 & 47 & $69.85[19.2]$ & $47.93[14.32]$ \\
\hline
\end{tabular}

EAL, English as an additional language; M, monolingual; SD, standard deviation. 
$t[32]=3.61, P=0.001$, two tailed). When examined by year group, the Mann-Whitney $U$-test again revealed significant differences between EAL and monolingual BPVS II scores for the formulation year $(\mathrm{U}=1.000, \mathrm{z}=-2.22, P=0.026)$ and Year $2(\mathrm{U}=1.000, \mathrm{z}=-3.003, P=0.003)$, but not for Year 1 . However, the Year 1 EAL group was probably too small $(n=3)$ for data analyses to identify differences. For the EAL children, there were also significant positive relationships between the BPVS II score and length of stay in the UK $(r=0.877, P=0.0001)$.

\section{PPA data}

The summary results for the PPA are presented at Table 1. Some cells are blank based on the class teacher's advice regarding the ability of children to understand the picture. The Year 2 children in both groups insisted on placing some of the pictures between two colors (noted as red/yellow or yellow/green in Table 2). In some instances, this was a way of the group gaining consensus, but for other pictures, it was an immediate judgement by the whole group.

The PPA demonstrated some differences between EAL and monolingual children, and between year groups. These differences were more noticeable with the recreation pictures; however, none of the pictures were rated the same by all six groups. This variation was classified as small (green and yellow/green), moderate (red and yellow, or yellow and green), or large (red, yellow and green, or red and green) (Table 2).
While responses to the pictures illustrating activities of daily living were similar between the EAL and monolingual groups, especially in the formulation year and Year 1, field notes identified noticeable differences between EAL and monolingual for the formulation year and Year 1 in terms of sex. This was marked for three pictures (dropping a bowling ball on foot, having a crash with a bicycle, and fighting with another child); in the monolingual groups, girls were more likely to put these pictures initially on the green paper and boys on the red.

Overall, monolingual children were less likely to discuss the reasons for picture placement. The Year 1 EAL children were particularly considered in their decision-making; for example, placement of pictures was considered in relation to longer-term effects: "it would hurt a lot, but it would get better soon" (burning hand on the stove, placed on green) and "it would hurt for a little time and then go away" (getting hit by the baseball while batting, placed on yellow).

The Year 1 monolingual children looked at pictures in relation to other pictures; for example, "it would hurt the same as that one" (pointing to another picture). Moreover, they gave reasons for their judgements about the degree of pain depicted; for example, the presence/likelihood of blood was a factor: "they wouldn't bleed, so it wouldn't hurt so much", as was the surface onto which the child fell: "it's concrete, so would hurt a lot", and the extent of the accident: "it is not very high (the tree), so should be green".

During the placement of the pictures with the group of Year 2 EAL children, when this group were shown the first

Table 2. Picture placement

\begin{tabular}{|c|c|c|c|c|c|c|c|}
\hline & \multicolumn{2}{|c|}{ Foundation year } & \multicolumn{2}{|c|}{ Year 1} & \multicolumn{2}{|c|}{ Year 2} & \multirow[b]{2}{*}{ Variation } \\
\hline & EAL & M & EAL & M & EAL & M & \\
\hline \multicolumn{8}{|l|}{ Recreation } \\
\hline Being hit by a baseball while batting & G & $\mathrm{Y}$ & G & G & $\mathrm{Y}$ & $\mathrm{R} / \mathrm{Y}$ & $\mathrm{L}$ \\
\hline Falling off a skateboard & $\mathrm{R}$ & $\mathrm{Y} \dagger$ & $\mathrm{R} \dagger$ & $\mathrm{Y} \dagger$ & $\mathrm{R}$ & $\mathrm{R}$ & M \\
\hline Having a crash with a bicycle & $\mathrm{R} \dagger$ & $(\mathrm{G})$ & $\mathrm{G} \dagger$ & $(\mathrm{R}) \dagger$ & $\mathrm{R} / \mathrm{Y} \dagger$ & $\mathrm{Y}$ & $\mathrm{L}$ \\
\hline Dropping a bowling ball on foot & $\mathrm{R}$ & (R) & $\mathrm{Y}$ & (R) & $\mathrm{R}$ & $\mathrm{R}$ & M \\
\hline Run over by another football player & $\mathrm{R}$ & $\mathrm{Y}$ & G & $\mathrm{G}$ & $\mathrm{R} / \mathrm{Y}$ & $\mathrm{Y}$ & $\mathrm{M}$ \\
\hline Falling out of a tree & $\mathrm{R} \dagger$ & $\mathrm{R}$ & $(\mathrm{Y})$ & (G) & $\mathrm{R}$ & $\mathrm{R} / \mathrm{Y} \dagger$ & M \\
\hline \multicolumn{8}{|l|}{ Activities of daily living } \\
\hline Closing a finger in a door & (Y) & G & $\mathrm{R}$ & $\mathrm{R} \dagger$ & $\mathrm{Y}$ & $\mathrm{R}$ & $\mathrm{L}$ \\
\hline Getting stung by bees & $\mathrm{R}$ & $\mathrm{R} \dagger$ & $(\mathrm{Y})$ & $\mathrm{Y}$ & $\mathrm{Y}$ & $\mathrm{R} \dagger$ & M \\
\hline Cutting hand while peeling fruit & $\mathrm{R}$ & $\mathrm{R}$ & $\mathrm{R} \dagger$ & $(\mathrm{G})$ & $\mathrm{R} \dagger$ & $\mathrm{R} \dagger$ & $\mathrm{L}$ \\
\hline Pulling off a band aid & & & & & $\mathrm{G}$ & $\mathrm{Y} / \mathrm{G}$ & $\mathrm{S}$ \\
\hline Burning hand on the stove & $\mathrm{R} \dagger$ & $(\mathrm{R}) \dagger$ & $(\mathrm{Y})$ & $\mathrm{Y}$ & $\mathrm{R}$ & $\mathrm{R}$ & M \\
\hline \multicolumn{8}{|l|}{ Psychosocial: } \\
\hline Being scolded by a policeman & & & & & $\mathrm{Y}$ & $\mathrm{R}$ & M \\
\hline Laughed at by schoolmates for misspelling & & & $(\mathrm{G})$ & $\mathrm{R}$ & $\mathrm{R} \dagger$ & $(\mathrm{Y})$ & $\mathrm{L}$ \\
\hline Striking out in a baseball game & & & & & $(\mathrm{R})$ & (R) & $\mathrm{n} / \mathrm{a}$ \\
\hline Reprimanded by a teacher & & & & & $\mathrm{Y}$ & $\mathrm{Y} / \mathrm{G}$ & S \\
\hline Fighting with another child & $\mathrm{G}^{\dagger}$ & $(\mathrm{R}) \dagger$ & $\mathrm{R}$ & $(\mathrm{R})$ & $\mathrm{Y} \dagger$ & G & $\mathrm{L}$ \\
\hline Being excluded from a game & & & & & $\mathrm{Y}$ & $\mathrm{G}^{\dagger}$ & M \\
\hline
\end{tabular}

$\dagger$ Selection of picture for group discussion, based on level of conversation generated. Variation is described as small (S), moderate (M) or large (L). (R), there was initial disagreement, but eventual consensus. Inclusion of two colors $(\mathrm{R} / \mathrm{Y})$ indicates that the group placed the picture between two papers. EAL, English as an additional language; G, green; M, monolingual; R, red; Y, yellow. 
picture (falling out of a tree), these children said "that's scary" and immediately said it should be placed on the red paper. They also had an immediate reaction to some pictures, particularly those that were scored red.

Overall, Year 2 monolingual children demonstrated greater understanding of the pictures, but EAL children across all year groups were more likely to describe the picture then decide where to put it, and all the children in the EAL groups wanted to talk. Of note, the EAL children did not revert to their primary language during the PPA or interviews. Despite the lower language scores for EAL children across year groups, this did not constrain their conversation during the PPA.

\section{Focus group interview data}

Analysis of the interviews and field notes recorded during the PPA revealed four types of narrative: (i) the words used to describe pain in the pictures; (ii) the children's suggestions for how pain would be managed for specific scenarios; (iii) judgements about the scenarios depicted; and (iv) personal stories triggered by the individual picture. Data excerpts for the narrative types are presented below, with notation indicating the group and picture that elicited the conversation (e.g. formulation year EAL/bike crash). Where the excerpt relates to a conversation between group members, participant numbers are noted (e.g. P2, P3, P7). The narrative analysis focused on both content and form (i.e. the way in which the story was told). Thus, the audiotapes were listened to again as part of the analysis.

\section{Words used to describe pain}

When asked how the child in the picture would describe their pain ("What would the child say to their mommy or daddy?"), vowel sounds ("eee", "oooh", "ouch", "owww") were used by all groups, regardless of the rating given to the picture; for example, Year 1 monolingual and EAL groups used the word "owww" for all pictures, but placed them on different colored sheets. The word "hurt" was used to describe pictures across year groups:

Ouch, that hurt really, really bad. (Year 1 monolingual/ bike)

That one hurt. (formulation year monolingual/burn)

0www, hurt me. (Year 2 EAL/fighting).

The narratives also described the impact of the injury; for example "(he would say) I hurt my head" (formulation year monolingual/skateboard). Across all three year groups, the EAL children gave more dramatic responses and referred to broken bones, as indicated in this conversation between participants: "(s/he would say) I broke my head...my arm ... my palm” (formulation year EAL/bike/P3, P5, P2).

\section{Managing pain}

When asked "what Mommy or Daddy would do", participants related two types of narratives: description of practical measures to relieve the pain and sanctions imposed because of the child's actions. Measures to reduce pain included those administered by parents; for example, "Put plaster on it" (Year 1 Monolingual/cut finger), "Mommy and Daddy would play with him" (Year 1 EAL/bike), "They would help him to spell better ... he (would) tell (sic) his Mommy and Dad 'Can you learn me (sic) how to write "cat"?', write it down lots of time" (Year 2/EAL/spelling mistake). For other scenarios, the children suggested involvement of a doctor, for example, "The doctor will fix him" (Year 2 EAL/bike), or a hospital, for example, "They might take him to hospital" (formulation year monolingual/skateboard), and for one group, involving the teacher: "Ask the teacher, because it's the teacher that helps the kids" (Year 2 monolingual/child excluded from game). The younger children were more likely to describe some form of sanction, such as "Mommy would take the back wheel off" (formulation year monolingual/skateboard) and "He wouldn't be allowed to ride again" (formulation year EAL/bike).

\section{Judgements about the scenario depicted}

The implication that some of the injuries might be selfinflicted ran through all the group discussions, with the phrase "that's naughty" used by most groups; for example, "That is naughty if you're climbing trees" (formulation year/ EAL). In some instances, the judgement of bad behavior was implied; for example, "You know that bees sting and they make honey, yellow, and he was sure he would get the honey, and the bees stinging him" (Year 2 monolingual/bee stings). In particular, the formulation year EAL group used the term "naughty" for all four of the pictures discussed. In contrast, the Year 2 monolingual group noted that someone else might be to blame for one of the scenarios: "Someone left the knife there" (Year 2 monolingual/cut finger). The notion of personal responsibility was also evident in the response to the picture showing a child being laughed at by schoolmates for misspelling a word, with the group suggesting that the child would say: "I am useless" (Year 2 EAL/spelling mistake).

The need for the child to legitimize the pain to parents, the doctor or the hospital was also raised in some of the groups:

You would need to prove to your Mommy and Daddy that you've really hurt yourself. (Year 1 monolingual/ finger in door)

The doctor would say "I'm going to close; come back later" because he's not really sick. (Year $1 \mathrm{EAL} /$ skateboard)

The hospital will say "you have to go home". (formulation year monolingual/burnt hand).

The consequences of the child's behavior was a recurrent point of discussion across the focus groups, ranging from "wake him" (formulation year monolingual/bee stings), implying that they were aware that bee stings could be dangerous, to "little fights can lead to big fights" (Year 2 EAL/ children fighting). 


\section{Personal narratives}

The children in the younger monolingual group were keen to share stories of their own painful experiences, and older EAL children were more likely to "story" their experiences of pain than the younger EAL children: "I burnt my back when I was doing skateboarding" (Year 1 EAL/skateboard fall). When shown the picture of the child excluded from a game, the Year 2 monolingual group all wanted to share similar experiences: "It happens to me when I was at school . . I always cry ..." (Year 2 monolingual/child excluded from game/P4, P5). Some groups were also keen to share stories about situations in which they were not harmed: "I have a nice skateboard, I did nice skating and I didn't fall over". Then another child said: "No, I was doing skating and it's easy; it's fun that skating" (formulation year monolingual/skateboard fall). In some instances the pictures triggered discussion about acceptable rules; for example "We not allowed fighting at school" (formulation year monolingual/children fighting). The personal stories were also more likely to draw other children into the narrative:

I told Mommy I get (sic) graze on it, (she) would say "never mind go back to school", (put on) cream and then a plaster. (P3)

Does that all your mommy probably do (sic); would say "never mind go back to school"? (P5)

Yup. (P3/formulation year/monolingual/bee sting)

With the exception of the "fighting" picture, personal stories were only shared in response to pictures where there was moderate agreement in the PPA.

Overall, the quality of the conversation was different across age and language groups; however, when reviewed in the context of BPVS II scores, this was not necessarily because of lexical competence. For example, the difference between language and age for monolingual and EAL children was not evident in the focus group discussions.

\section{DISCUSSION}

The aim of this study was to examine how children from different language backgrounds talk about pain. This was addressed through a PPA and focus group interviews. Pictures from the Pediatric Pain Inventory (Lollar et al., 1982) were used for both stages of data collection. Our findings revealed a number of differences in the ways in which children talked about pain. Some differences were linked to the background, age or sex of the children. Sex differences in pain reporting have been reported previously in studies with adults (Woodrow et al., 1972; Brooks-Brunn \& Kelser, 2000; Miller \& Newton, 2006; Koffman et al., 2008); our data indicated that these differences might be evident from an early age. Theorists distinguish between language acquisition (learning a language) and language socialization (appropriate use of language in a social context) (Schieffelin \& Ochs, 1986). Competence in a language is said to exist when the speaker can convey feelings and recognize the mood or emotion of others through language (Hornberger \& McKay,
2010). Our data indicated that there were differences in the way in which children from monolingual and EAL backgrounds talked about pain, as demonstrated in an earlier study (Parke, 2001). However, the absence of reversion to primary language indicates that the use of interpreters might be of limited value in this age group. Further, the BPVS II data demonstrated that a number of factors (i.e. length of stay in the country) might influence the language ability of children in this age group. Thus, when assessing pain, it is important to take these factors into account.

In the extent to which narratives provide insight into how children make sense of their world (Engel, 2005), there were a few points of interest in the findings. The narratives confirmed findings of previous studies that parents play an active role in their child's pain assessment and management (Hallström and Elander, 2004; Liossi et al. 2012). The use of similar words to describe pain in pictures that were put on different colored paper emphasized the limited use of vocabulary for distinguishing between pain intensity; this has been reported previously (Selzer, 2011). Overall, the quality of the conversation was different across age and language groups; however, when reviewed in the context of BPVS II scores, this was not necessarily because of lexical competence. This is in contrast to the findings of Lollar et al's (1982) original study with hospitalized children, where psychosocial pain was perceived as significantly less intense than other types of pain.

In this study, younger children verbalized pain in response to most of the pictures, without considering the intensity level of pain presented in the picture. In contrast, older children used a richer vocabulary. This is in contrast to a previous study with 58 children of a similar age (4.8-8.3 years), where older children were less likely to verbalize pain than younger children (Stanford et al., 2005).

\section{Limitations}

The largest difference in language ability in these study participants, as measured by the BPVS II, was in children aged 4-5 years and those aged 6-7 years. However, given the smaller number of children in the 5-6 year age group, the possibility of a type II error cannot be ruled out. The EAL children were from different linguistic backgrounds; it is possible that consensus might have been achieved for more pictures had the children spoken the same language. EAL children might have a richer storytelling culture; no attempt was made to measure this in this study.

The study participants were (ostensibly healthy) children attending school, thus the discussion focused on how they described the pain of children in the pictures. The findings might be different if the study was undertaken with hospitalized children with recent experience of pain.

\section{Conclusions}

It is not possible to extrapolate from these findings how variation in language would apply if children were reporting their own pain. However, the findings emphasize the need for sufficient time to be allocated to pain assessment to allow an 
individualized approach. The study findings suggest several factors that might be important in reporting pain with EAL children, such as sex, cultural background, and language ability; these should be explored in the context of clinicians' assessment of pain.

\section{CONTRIBUTIONS}

Study Design: PA, RE, AC, AH.

Data Collection and Analysis: PA, RE.

Manuscript Writing: PA, RE, AC, AH.

\section{REFERENCES}

American Academy of Pediatrics: American Pain Society. The assessment and management of acute pain in infants, children and adolescents. Pediatrics 2001; 108: 793-797.

Azize PM, Humphreys A, Cattani A. The impact of language on the expression and assessment of pain in children. Intensive Crit. Care Nurs. 2011; 27: 235-243.

Bates MS, Edwards WT, Anderson KO. Ethnocultural influences on variation in chronic pain perception. Pain 1993; 52: 101112.

Bochner PA. It's about time: narrative and the divided self. Qual. Inq. 1997; 3: 418-438.

Bonham VL. Race, ethnicity and pain treatment: striving to understand the causes and solutions to the disparities in pain treatment. J. Law Med. Ethics 2001; 29: 52-68.

Brooks-Brunn A, Kelser KA. Gender differences in self-reported pain following thoracic resection. Chest 2000; 118: 205-206.

Chan LLS, Sylva K. An exploration of assessment of early English language development for kindergarten children in Hong Kong. APERA Conference, 28-30 November 2006. [Cited 30 Apr 2012.] Available from URL: http://edisdat.ied.edu.hk/pubarch/ b15907314/full_paper/1292382624.pdf.

Coyne I. Consultation with children in hospital: children, parents' and nurses' perspectives. J. Clin. Nurs. 2006; 15: 61-71.

Creswell JW, Plano Clark VL. Designing and Conducting Mixed Methods Research. London: Sage, 2007.

Doyle K. Ethical Considerations in Researching Children. Chicago: Doyle Research Associates. Marketing Research Association, 2000.

Drendel AL, Brousseau DC, Gorelick MH. Pain assessment for pediatric patients in the emergency department. Pediatrics 2006; 117: $1511-1518$.

Dunn LM, Dunn LM, Whetton C, Burley J. The British Picture Vocabulary Scale (2nd edn) Manual. London: nfer Nelson Publishing Company Ltd, 1997.

Edwards RR, Doleys DM, Fillingim RB, Lowery D. Ethnic differences in pain tolerance: clinical implications in a chronic pain population. Psychosom. Med. 2001; 63: 316-322.

Engel S. Narrative analysis of children's experiences. In: Green S, Hogan D (eds). Researching Children's Experience: Approaches and Methods. London: Sage, 2005; 199-216.

Espinosa L. Curriculum and assessment consideration for young children from culturally, linguistically, and economically diverse backgrounds. Psychol. Sch. 2005; 42: 837-853.
Fortier MA, Anderson CT, Kain ZN. Ethnicity matters in the assessment and treatment of children's pain. Pediatrics 2009; 124: 378380.

Green CR, Anderson KO, Baker TA et al. The unequal burden of pain: confronting racial and ethnic disparities in pain. Pain Med. 2003; 4: 277-294.

Hadjistavropoulos T, Craig KD. A theoretical framework for understanding self-report and observational measures of pain: a communications model. Behav. Res. Ther. 2002; 40: 551-570.

Hallström I and Elander G. Decision-making during hospitalization: parents' and children's involvement. J Clin. Nurs. 2004; 13: 367375.

Hoppe MJ, Wells EA, Morrison DM et al. Using focus groups to discuss sensitive topics with children. Eval. Rev. 1995; 19: 102114.

Hornberger NH, McKay SL. Sociolinguistics and Language Education Multilingual Matters. Washington, DC: Library of Congress, 2010.

Koffman J, Morgan M, Edmonds P, Speck P, Higginson IJ. Cultural meanings of pain: a qualitative study of Black Caribbean and White British patients with advanced cancer. Palliat. Med. 2008; 22: 350-359.

Liossi C, Noble G, Franck LS. How parents make sense of their young children's expressions of everyday pain: A qualitative analysis. Eur. J. Pain. 2012; 16: 1166-1175.

Lollar DJ, Smits SJ, Patterson DL. Assessment of pediatric pain: an empirical perspective. J. Pediatr. Psychol. 1982; 22: 267-277.

McCaffery M, Beebe A. Pain: Clinical Manual for Nursing Practice. St Louis, MO: Mosby, 1989.

Miller C, Newton SE. Pain perception and expression: the influence of gender, personal self-efficacy, and lifespan socialization. Pain Manag. Nurs. 2006; 7: 148-152.

Parke T. Words and turns: bilingual and monolingual children construct a story. Linguist. Educ. 2001; 12: 409-430.

Perez C, Tager-Flusberg H. Clinicians' perceptions of children's oral personal narratives. Narrative Inq. 1998; 8: 181-201.

Schieffelin BB, Ochs E. Language socialization. Annu. Rev. Anthropol. 1986; 15: 163-191.

Selzer R. The language of pain. 2011 [Cited 05 August 2013.] Available from URL: http://www.courses.vcu.edu/ENG200-dwc/ selzer.htm.

Stalnikowicz R, Mahamid R, Kaspi S, Brezis M. Under treatment of acute pain in the emergency department: a challenge. J. Qual. Health Care 2005; 17: 173-176.

Stanford EA, Chambers CT, Craig KD, McGrath PJ, Cassidy KL. "Ow!": spontaneous verbal pain expression among young children during immunization. Clin. J. Pain 2005; 21: 499-502.

Subhashini L, Vatsa M, Lodha R. Knowledge, attitude and practices among health care professionals regarding pain. Indian J. Pediatr. 2009; 76: 913-916.

Taylor EM, Boyer K, Campbell FA. Pain in hospitalized children: a prospective cross-sectional survey of pain prevalence, intensity, assessment and management in a Canadian pediatric teaching hospital. Pain Research \& Management 2008; 13: 25-32.

Van Maanen J. Tales of the Field: On Writing Ethnography. Chicago, IL: University of Chicago Press, 1988.

Woodrow KM, Friedman GD, Siegelaub AB, Collen MF. Pain tolerance: differences according to age, sex and race. Psychosom. Med. 1972; 34: 548-556.

Zinke J. Culture, pain and pain research. Am. Pain Soc. Bull. 2007; 17: 1 . 